\title{
Study of the distribution and abundance of the eggs of Aedes aegypti and Aedes albopictus according to the habitat and meteorological variables, municipality of São Sebastião, São Paulo State, Brazil
}

Lígia Leandro Nunes Serpa ${ }^{1 *}$, Gisela Rita Alvarenga Monteiro Marques, Ana Paula de Lima', Júlio Cesar Voltolini², Marylene de Brito Arduino ${ }^{1}$, Gerson Laurindo Barbosa ${ }^{3}$, Valmir Roberto Andrade ${ }^{4}$ and Virgília Luna Castor de Lima ${ }^{4}$

\begin{abstract}
Background: This study focused on the distribution and abundance of the eggs of Aedes aegypti and Aedes albopictus.

Methods: Eighty ovitraps were exposed for four days of each month in peri- and intradomiciliary environments of 40 urban residences on 20 street blocks that were drawn monthly in Sebastião, SP, between February 2011 and February 2012. The monthly distribution of positive ovitrap indices (POI) and mean egg counts per trap (MET) of Ae. aegypti and Ae. albopictus were analyzed using the Kruskal-Wallis test, followed by the Dwass-Steel-Critchlow-Fligner (DSCF) test. Spearman's rank correlation coefficient and simple linear regression were used to determine the association between the meteorological variables of temperature and rainfall and the number of ovitraps with eggs and the egg count.

Results: The POI and MET of Ae. aegypti were higher in peridomiciliary premises. A positive correlation was found between the temperature and the number of ovitraps with eggs and the egg count of this species in domestic environments. There was no difference in the POI and MET of Ae. albopictus between the environments. A positive correlation was found between temperature and positive ovitraps of Ae. albopictus in peridomiciliary premises. The $\mathrm{POI}$ and MET of Ae. aegypti were higher than those of Ae. albopictus.
\end{abstract}

Conclusions: Peridomiciliary premises were the preferred environments for oviposition of Ae. aegypti. The use of ovitraps for surveillance and vector control is reiterated.

Keywords: Aedes, Environment, Mosquito control, Dengue, Oviposition, Meteorological factors

\section{Background}

The mosquitoes responsible for the transmission of the dengue virus, Aedes aegypti (Linnaeus) and Aedes albopictus (Skuse), are considered important vectors of the arbovirosis. These species present abundance influenced by the female behavior of oviposition, as well as their temporal space distribution, which has predominant

\footnotetext{
* Correspondence: ligia-serpa@hotmail.com

'Superintendência de Controle de Endemias, Praça Coronel Vitoriano, 23 Jardim Santa Clara, Centro, Taubaté, São Paulo CEP 12020-020, Brasil Full list of author information is available at the end of the article
}

dependency on the environment and the local climate in which they occur, with female mosquitoes searching for conditions favourable to survival of progeny [1].

In Brazil, dengue fever has become one of the key public health priorities since the late 1990s because its occurrence is directly related to various factors, including the level of local infestation by the vector $[2,3]$.

Ae. aegypti and Ae. albopictus are the only Culicidae species of the Stegomyia genus found in Brazil [4]. In São Paulo State in the year 2012, 87\% of the municipalities exhibited co-occurrence of these mosquitoes, 
according to data from the Superintendence for Endemic Disease Control (Superintendência de Controle de Endemias, Sucen). The population dynamics of adult Ae. aegypti is highly significant in the epidemiology of the dengue infection, thus directing the scientific community's efforts towards elucidating this aspect, which is inherent to control expectations $[5,6]$.

The abundance of these vectors is associated with biotic and abiotic factors. According to Braks et al. [4], the spatial distribution and abundance of Ae. aegypti are related to the effects of anthropogenic changes on the environment. Conversely, the distribution of Ae. albopictus is more associated with the presence of vegetation in urban and rural areas, whereas its abundance is generally limited to spaces modified by human activity. Among the environmental variables, rainfall, temperature, and relative humidity are key determining factors of the presence and frequency of these species [7]. According to Focks et al. [8], meteorological factors affect the mosquito metabolism, oviposition activity, and consequently, the number of eggs laid by females. Such bioecological aspects may be measured in positive ovitraps and egg density, as previously shown by Azil et al. [7].

In the entomological surveillance and control of dengue vectors, the likelihood of arbovirus transmission among humans is high, although it will always depend on the habits and densities of the species involved. The study of practical and operational methods using ovitraps may provide such information, which is beneficial for planning and managing the vector [9]. The ovitrap [10] is a useful tool for providing spatial and temporal data and successfully monitors the impact of control measures. Ovitrap use was recommended for differentiating infestation levels between areas, making it more sensitive than the larval survey currently used, even during low levels of vector population $[7,11,12]$.

Ae. aegypti mosquito control mainly occurs on peridomiciliary breeding grounds, although it is unclear whether the distribution of outbreaks only results from a small supply of intradomiciliary water containers or also results from the preference for oviposition in peridomiciliary premises $[13,14]$.

Certain studies have revealed a higher occurrence of Ae. albopictus in peridomiciles $[15,16]$ and the prevalence of $A e$. aegypti is either indistinguishable between both environments [16-18] or even more frequent in peridomiciliary premises [19].

Mosquito behavior in the field is a key factor in the epidemiology of diseases transmitted by mosquitoes. Different patterns of habitat occupation may be observed between these species or within a given species, albeit in different regions [20]. The coastal region of São Paulo State exhibits diverse climate characteristics [21]. The municipality of São Sebastião, a north-shore tourist resort where infestation by Ae. albopictus began in the early 1980 s and infestation by Ae. aegypti began in the second half of the 1990s [22], is located in this region. Its climate, according to the Center for Meteorology and Climate Research Applied to Agriculture (Centro de Pesquisas Meteorológicas e Climáticas Aplicadas à Agricultura; CEPAGRI), is tropical rainy, without a dry season and with mild temperatures throughout the year. São Sebastião has high human-population fluctuation and successive records of dengue epidemics since 2001, and the serotypes DENV 1, DENV 2, DENV 3 [23], and, more recently, DENV 4 were isolated during that period, according to the SES/SP Vigilância Epidemiológica CVE 2013). Accordingly, it is crucial to examine the infestations by Ae. aegypti and Ae. albopictus in this municipality. To this end, the present study aimed to characterize the distribution and abundance of these species in periand intradomiciliary environments and to determine the association with meteorological factors to foster improvements in vector control measures.

\section{Methods \\ Study area}

The present study was conducted in an urban area of the municipality of São Sebastião $\left(45^{\circ} 21^{\prime} 00^{\prime \prime} \mathrm{W}\right.$ and $23^{\circ} 21^{\prime}$ $20^{\prime \prime}$ ), on the northern coast of São Paulo State, Brazil. This municipality has a territory of approximately 400 $\mathrm{Km}^{2}$, with a population of 73,942 inhabitants, according to data from the Brazilian Institute of Geography and Statistics, and a population density of 184.68 inhabitants $/ \mathrm{Km}^{2}$. São Sebastião has a coastal plain terrain with an average altitude of $10 \mathrm{~m}$ above sea level and an average annual temperature of approximately $24^{\circ} \mathrm{C}$. According to the simplified Köppen Climate Classification System (CCS) [24], São Sebastião has an Af climate, which is characterized by the tropical rainy climate that has no dry season and an average rainfall below $60 \mathrm{~mm}$ in the driest month. Its urban area crosses the boundaries of the plains and invades the coastal mountains, a situation that results from the intense and disordered process of occupation pressured by the growth of the fluctuating tourist and urbanresident populations, which contributes to worsening the local basic sanitation services [23].

The area selected for the present study corresponds to part of the urban space and was termed Area 1 (Figure 1). This area consists of 532 street blocks, 16,833 properties, and a population of approximately 40,116 inhabitants, according to data from the Brazilian Institute of Geography and Statistics (Instituto Brasileiro de Geografia e Estatística; IBGE, 2010).

\section{Study design}

The sample unit was the property, the street block of which was selected by systematic, random, and monthly 


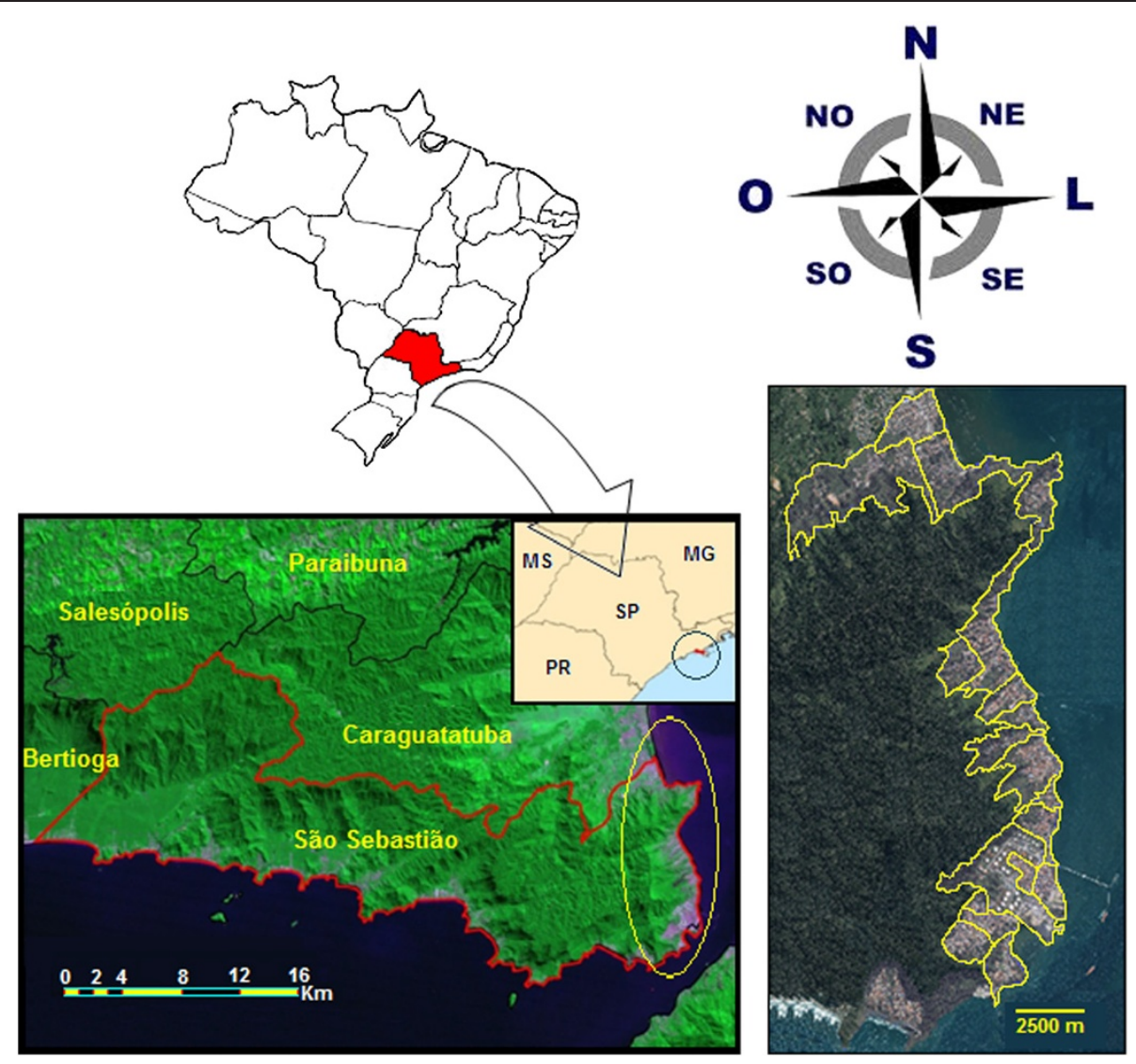

Figure 1 Image of the study area in the municipality of São Sebastião.

single-stage cluster sampling with replacement [25]. Two properties were selected from each block drawn, considering the greatest distance between them. Two ovitraps were installed in these human habitations, after obtaining the owner's informed consent: one in peridomiciliary premises and the other in intradomiciliary premises, approximately $1.20 \mathrm{~m}$ above the floor [26]. Peridomiciliary refers to the exterior of the building, albeit limited to the immediate vicinity of the house, while intradomiciliary refers to areas within the house, under its roof.

The trap consists of a black plastic material $(10.5 \mathrm{~cm}$ in diameter and $15 \mathrm{~cm}$ in height) filled with $450 \mathrm{ml}$ of tap water and $50 \mathrm{ml}$ of hay infusion [27]. A removable pressed wood pallet (Eucatex ${ }^{\circ} ; 15 \mathrm{~cm} \times 2.5 \mathrm{~cm}$ ) was placed within the trap as an oviposition substrate (Figure 2). The traps remained exposed for four consecutive days each month [28], from February 2011 to February 2012. Following each exposure period, the pallets were collected, and the attached eggs were counted and recorded. To ensure embryogenesis, the pallets were kept on the bench for six days at room temperature and relative humidity. Subsequently, the eggs were immersed in running water in plastic cups $(9 \mathrm{~cm} \times 11 \mathrm{~cm} \times 6 \mathrm{~cm})$,

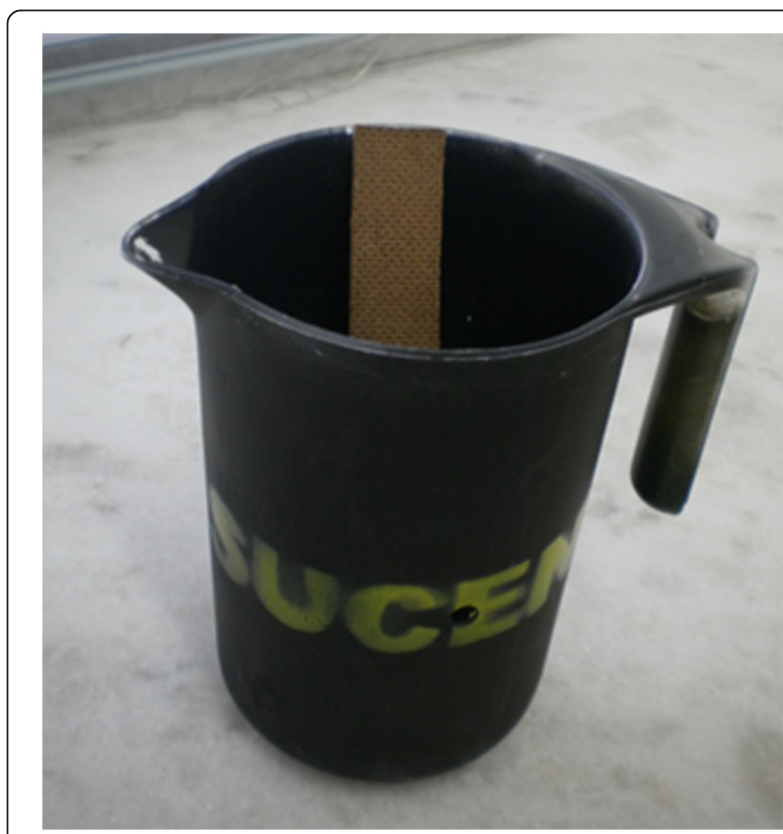

Figure 2 llustrative photo of the ovitrap with oviposition substratum. 
supplemented with a portion of Goldfish ${ }^{\circ}$ feed, and covered in film. At the L3 or L4 stage, the larvae were fixed in $70 \%$ ethanol and identified [29].

\section{Data analyses}

The measures of infestation by populations of $A e$. aegypti and Ae. albopictus eggs were expressed using the positive ovitrap index (POI; frequency of positive traps) and mean eggs per trap (MET).

Spearman's rank correlation coefficient was used to evaluate the association between the POI and MET of Ae. (Ste.) spp.

The Kruskal-Wallis test and the Dwass-Steel-CritchlowFligner (DSCF) test [30] were used to evaluate the POI and MET monthly distributions according to the environment.

Spearman's rank correlation coefficient and simple linear regression were used to determine the association between the meteorological variables of minimum average, maximum average, and average temperatures; the total and average rainfall during the four days of trap exposure; and the number of traps with eggs and the egg count according to the species and environment.

Spearman's rank correlation coefficient was used to express the correlation between the rainfall accumulated during the least rainy months (February and from May to October) and during the rainiest months (March, April, and from November to January) and the egg count during the respective periods.

Abiotic data regarding temperature and rainfall were collected from the Center of Integrated Agrometeorological Data (Centro integrado de informações agrometeorológicas, CIIAGRO) of the Department of Agriculture, Livestock, and Food Supply of the State of Sao Paulo Government (Secretaria de Agricultura e Abastecimento do Governo do Estado de São Paulo) of the São Sebastião municipal station.

\section{Results}

In total, 1,040 traps were installed and 1028 recovered, and 255 (24.81\%) traps showed the presence of Ae. (Stegomyia) spp. eggs, including 182 (71.37\%) positive traps in the peridomiciliary premises and $73(28.63 \%)$ positive traps in the intradomiciliary premises, following examination. Of the total 20,264 eggs, 16,217 (80.00\%) were recovered in peridomiciliary premises, and 4,047 $(20.00 \%)$ were recovered in intradomiciliary premises. The immersion of all of these eggs enabled the identification of both species, namely, Ae. aegypti and Ae. albopictus.

Of the total positive traps $(\mathrm{n}=255), 190(74.51 \%)$ corresponded to the above-mentioned species, including 89.50\% $(\mathrm{n}=170)$ for Ae. aegypti and $10.50 \%(\mathrm{n}=20)$ for Ae. albopictus. The distribution of these traps, according to the peri- and intradomiciliary environments, corresponded to $74.70 \%$ and $25.30 \%$ for Ae. aegypti and $75.00 \%$ and $25.00 \%$ for Ae. albopictus, respectively.
Of the remaining $65(25,49 \%)$ positive traps, 30 (11.76\%) presented the co-occurrence of Ae. aegypti and Ae. albopictus species, and 35 (13.73\%) exhibited no larval hatching. The trap data of the species co-occurrence is included in an ongoing study and is not the focus of the present study.

The 190 pallets with single-species hatching of either $A e$. aegypti or Ae. albopictus exhibited combined larval hatching of 59.53\% ( $\mathrm{n}=8.851)$ of the 14,868 eggs collected. Eight thousand and fifty-eight larvae were identified in traps with Ae. aegypti, with $78.00 \%$ in peridomiciliary premises and $22.00 \%$ in intradomiciliary premises. In total, 793 hatched larvae were found in traps with Ae. albopictus, including $80.00 \%$ and $20.00 \%$ in the peri- and intradomiciliary premises, respectively.

Table 1 presents the POI and MET comparisons. The statistical analysis comparing the POI between the environments and species revealed significant differences $(\mathrm{H}=30.51, \mathrm{p}=0.00)$. The POI of Ae. aegypt $i$ was noticeably higher than the POI of Ae. albopictus in both environments (peridomiciliary $\mathrm{p}=0.00$ and intradomiciliary $\mathrm{p}=0.00$ ). The POI of Ae. aegypti in the peridomiciliary premises was noticeably higher than in the intradomiciliary premises $(\mathrm{p}=0.03)$. In contrast, the POI of $A e$. albopictus was similar in both domiciliary environments $(\mathrm{p}=0.33)$.

The mean eggs per trap (MET) and per environment presented statistically significant differences between the species and the environments $(\mathrm{H}=27.60, \mathrm{p}=0.00)$. The multiple comparison demonstrated that the MET of Ae. aegypti was significantly greater than the MET of Ae. albopictus in the peridomiciliary $(\mathrm{p}=0.00)$ and intradomiciliary $(\mathrm{p}=0.01)$ premises.

The peridomiciliary environment had the highest MET of Ae. aegypti ( $\mathrm{p}=0.03)$, whereas no statistically significant difference $(\mathrm{p}=0.57)$ was found between environments for Ae. albopictus. Table 1 lists the ratios of these species per environment. The POI and MET of Ae. aegypti were approximately three times higher in peridomiciliary than in intradomiciliary premises. Similar values of the same variables were found for the Ae. albopictus species but were not significant. The ratio between species revealed that the POI of Ae. aegypti was eight times higher than the POI of Ae. albopictus in the peridomiciliary premises and nine times higher in the intradomiciliary premises. Similar results were found for the MET, albeit with greater values: 9.50 times higher in the peridomiciliary premises and 11.80 times higher in the intradomiciliary premises.

The ratio of Ae. aegypti eggs was 3.70 in peridomiciliary environments and 1.00 in intradomiciliary environments, whereas the ratio of Ae. albopictus eggs was 4.05 in peridomiciliary environments and 1.00 in intradomiciliary environments.

Table 2 presents the analysis of Spearman's rank correlation coefficient and simple linear regression calculations 
Table 1 Comparisons of POI and MET between the Ae. aegypti and Ae. albopictus species according to the peri- and intradomiciliary environments in the municipality of São Sebastião, from February 2011 to February 2012

\begin{tabular}{|c|c|c|c|c|c|c|c|}
\hline \multirow[t]{2}{*}{ Species } & \multirow[t]{2}{*}{ Environment } & \multicolumn{3}{|l|}{ POI } & \multicolumn{3}{|l|}{ MET } \\
\hline & & Mean \pm Standard deviation & $\mathbf{p}$ & Ratio & Mean \pm Standard deviation & $\mathbf{p}$ & Ratio \\
\hline Ae. aegypti & Peridomiciliary & $24,52 \pm 4,18$ & 0,03 & & $12,12 \pm 2,98$ & 0,03 & \\
\hline$x$ & $x$ & $x$ & & $2,92: 1,00$ & $x$ & & $3,55: 1,00$ \\
\hline Ae. aegypti & Intradomiciliary & $8,41 \pm 1,76$ & & & $3,41 \pm 0,94$ & & \\
\hline Ae. albopictus & Peridomiciliary & $2,96 \pm 0,91$ & 0,33 & & $1,27 \pm 0,48$ & 0,57 & \\
\hline$x$ & $x$ & $x$ & & $3,18: 1,00$ & $x$ & & $4,38: 1,00$ \\
\hline Ae. albopictus & Intradomiciliary & $0,93 \pm 0,44$ & & & $0,29 \pm 0,16$ & & \\
\hline Ae. aegypti & Peridomiciliary & $24,52 \pm 4,18$ & 0,00 & & $12,12 \pm 2,98$ & 0,00 & \\
\hline$x$ & $x$ & $x$ & & $8,28: 1,00$ & $x$ & & $9,54: 1,00$ \\
\hline Ae. albopictus & Peridomiciliary & $2,96 \pm 0,91$ & & & $1,27 \pm 0,48$ & & \\
\hline Ae. aegypti & Intradomiciliary & $8,41 \pm 1,76$ & 0,00 & & $3,41 \pm 0,94$ & 0,01 & \\
\hline$x$ & $x$ & $x$ & & $9,04: 1,00$ & $x$ & & $11,76: 1,00$ \\
\hline Ae. albopictus & Intradomiciliary & $0,93 \pm 0,44$ & & & $0,29 \pm 0,16$ & & \\
\hline
\end{tabular}

between the number of traps with eggs and the egg count per species and environment in relation to the minimum, maximum, and average temperatures. A positive correlation was found for the number of traps with Ae. aegypti and the egg count with the minimum, maximum, and average temperatures in the peridomiciliary premises, and a statistically significant correlation with the maximum and average temperatures was found in the intradomiciliary premises. Regarding Ae. albopictus, a positive correlation was found between the maximum temperature and

Table 2 Spearman's rank correlation coefficient and simple linear regression between the temperature and rainfall and the number of traps with eggs and egg count per trap, according to the Ae. aegypti and Ae. albopictus species and peri- and intradomiciliary environments in the municipality of São Sebastião, from February 2011 to February 2012

\begin{tabular}{|c|c|c|c|c|c|c|c|}
\hline \multirow{2}{*}{$\begin{array}{l}\text { Number of traps } \\
\text { with eggs and } \\
\text { the egg count }\end{array}$} & \multirow{2}{*}{$\begin{array}{l}\text { Meteorological } \\
\text { variables }\end{array}$} & \multicolumn{3}{|c|}{ Ae. aegypti } & \multicolumn{3}{|c|}{ Ae. albopictus } \\
\hline & & $r$ & $r^{2}$ & $p$ & $r$ & $r^{2}$ & $p$ \\
\hline \multirow[t]{5}{*}{ Traps peridomiciliary } & Minimum $\mathrm{T}^{\circ} \mathrm{C}$ & 0.67 & 0.45 & 0.01 & 0.38 & 0.14 & 0.20 \\
\hline & Maximum $\mathrm{T}^{\circ} \mathrm{C}$ & 0.76 & 0.58 & 0.00 & 0.58 & 0.33 & 0.04 \\
\hline & $\mathrm{T}^{\circ} \mathrm{C}$ average & 0.76 & 0.58 & 0.00 & 0.52 & 0.27 & 0.07 \\
\hline & Total rainfall & 0.49 & 0.24 & 0.09 & -0.16 & 0.02 & 0.61 \\
\hline & Average rainfall & 0.49 & 0.24 & 0.09 & -0.16 & 0.02 & 0.61 \\
\hline \multirow[t]{5}{*}{ Traps intradomiciliary } & Minimum $\mathrm{T}^{\circ} \mathrm{C}$ & 0.34 & 0.12 & 0.25 & 0.34 & 0.11 & 0.26 \\
\hline & Maximum $\mathrm{T}^{\circ} \mathrm{C}$ & 0.69 & 0.47 & 0.01 & 0.28 & 0.08 & 0.36 \\
\hline & Average $\mathrm{T}^{\circ} \mathrm{C}$ & 0.57 & 0.32 & 0.04 & 0.32 & 0.10 & 0.29 \\
\hline & Total rainfall & 0.15 & 0.02 & 0.61 & 0.49 & 0.24 & 0.09 \\
\hline & Average rainfall & 0.15 & 0.02 & 0.61 & 0.49 & 0.24 & 0.09 \\
\hline \multirow[t]{5}{*}{ Eggs peridomiciliary } & Minimum $\mathrm{T}^{\circ} \mathrm{C}$ & 0.62 & 0.39 & 0.02 & 0.39 & 0.15 & 0.19 \\
\hline & Maximum $\mathrm{T}^{\circ} \mathrm{C}$ & 0.67 & 0.44 & 0.01 & 0.52 & 0.27 & 0.07 \\
\hline & Average $\mathrm{T}^{\circ} \mathrm{C}$ & 0.68 & 0.47 & 0.01 & 0.49 & 0.24 & 0.09 \\
\hline & Total rainfall & 0.49 & 0.24 & 0.09 & -0.24 & 0.06 & 0.43 \\
\hline & Average rainfall & 0.49 & 0.24 & 0.09 & -0.24 & 0.06 & 0.43 \\
\hline \multirow[t]{5}{*}{ Eggs intradomiciliary } & Minimum $\mathrm{T}^{\circ} \mathrm{C}$ & 0.45 & 0.20 & 0.12 & 0.14 & 0.02 & 0.65 \\
\hline & Maximum $\mathrm{T}^{\circ} \mathrm{C}$ & 0.66 & 0.43 & 0.01 & 0.19 & 0.04 & 0.52 \\
\hline & Average $\mathrm{T}^{\circ} \mathrm{C}$ & 0.60 & 0.36 & 0.03 & 0.18 & 0.03 & 0.55 \\
\hline & Total rainfall & 0.26 & 0.07 & 0.38 & 0.26 & 0.07 & 0.40 \\
\hline & Average rainfall & 0.26 & 0.07 & 0.38 & 0.26 & 0.07 & 0.40 \\
\hline
\end{tabular}


the number of traps with eggs in the peridomiciliary premises. No other correlations of these species were significant.

The presence of Ae. albopictus during the study period was small, although this species occurred in both domiciliary environments, either simultaneously or alternating between them. The absence of Ae. aegypti eggs in the traps occurred in September and only in the intradomiciliary premises.

Figure 3 displays the POI monthly distribution of $A e$. aegypti (A) and the POI of Ae. albopictus (B) per domiciliary environment. The presence of Ae. aegypti in peridomiciliary environments was recorded from the first to the last collection, with two significant peaks in February 2011 (51.22\%) and January 2012 (45.24\%). A decrease in the values was noted from March (35.90\%), with the lowest index in September (2.50\%), which then increased after October (16.67\%).

The absence of Ae. albopictus was noted from June to November in peridomiciliary premises, from April to
October in intradomiciliary premises, and subsequently in December and February. The peaks of this species in the peridomiciliary premises were recorded in May, December, and January. Conversely, this species peaked in the intradomiciliary premises in November.

The egg density, expressed by the MET, ranged monthly for both species, with the lowest mean of $A e$. aegypti eggs per trap (0.21) recorded in August and the highest mean (40.66) recorded in February 2011 in the peridomiciliary premises. The highest recorded value in the intradomiciliary premises (12.66) occurred in February 2011 (Figure 3C).

The highest MET of Ae. albopictus in peridomiciliary premises was recorded in February 2012 (4.26) and in intradomiciliary premises in November 2011 (2.10) (Figure 3D).

The comparison between the monthly distributions of the Ae. aegypti POI and the Ae. albopictus POI in the same domiciliary environment is presented in Figure 4

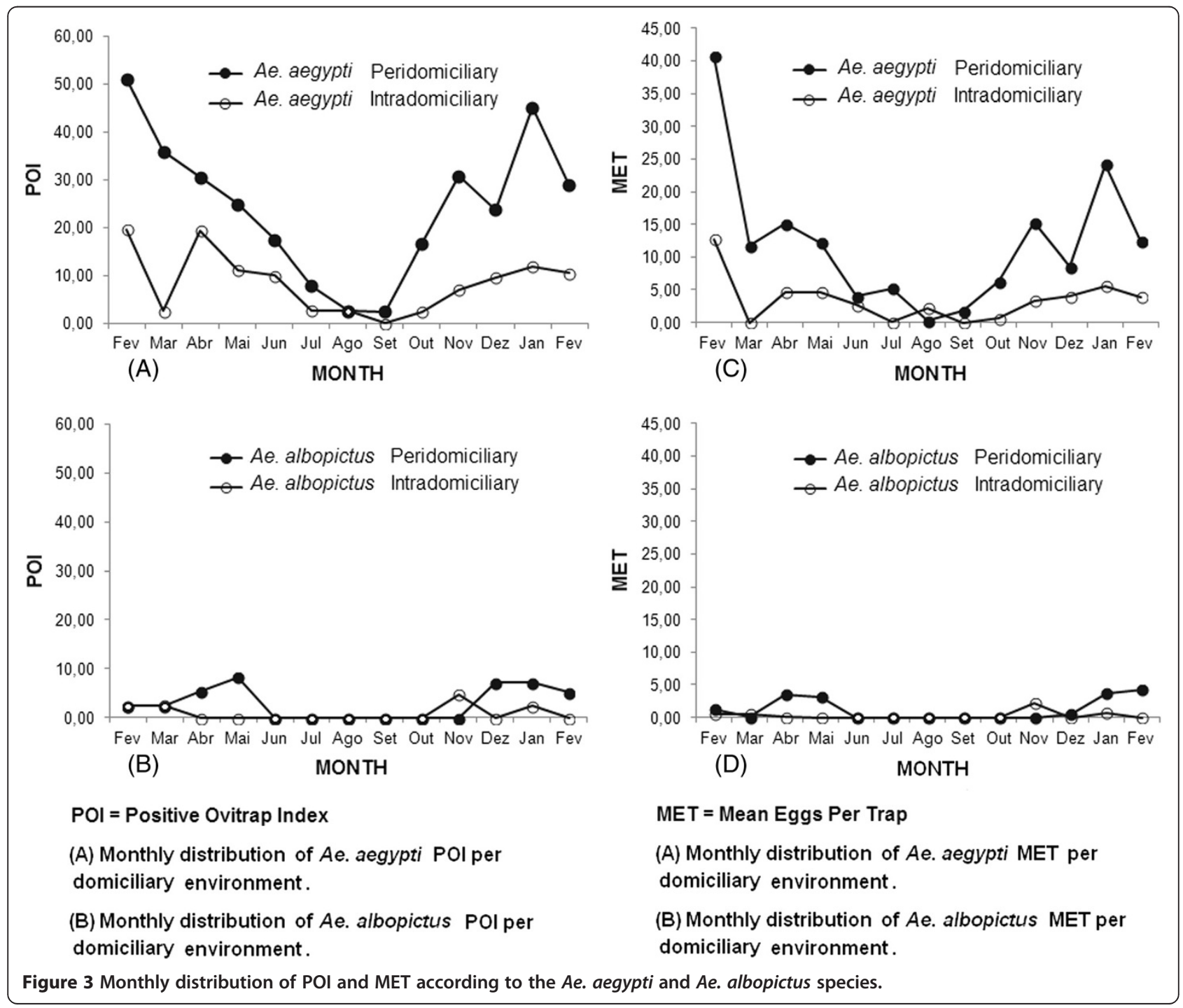




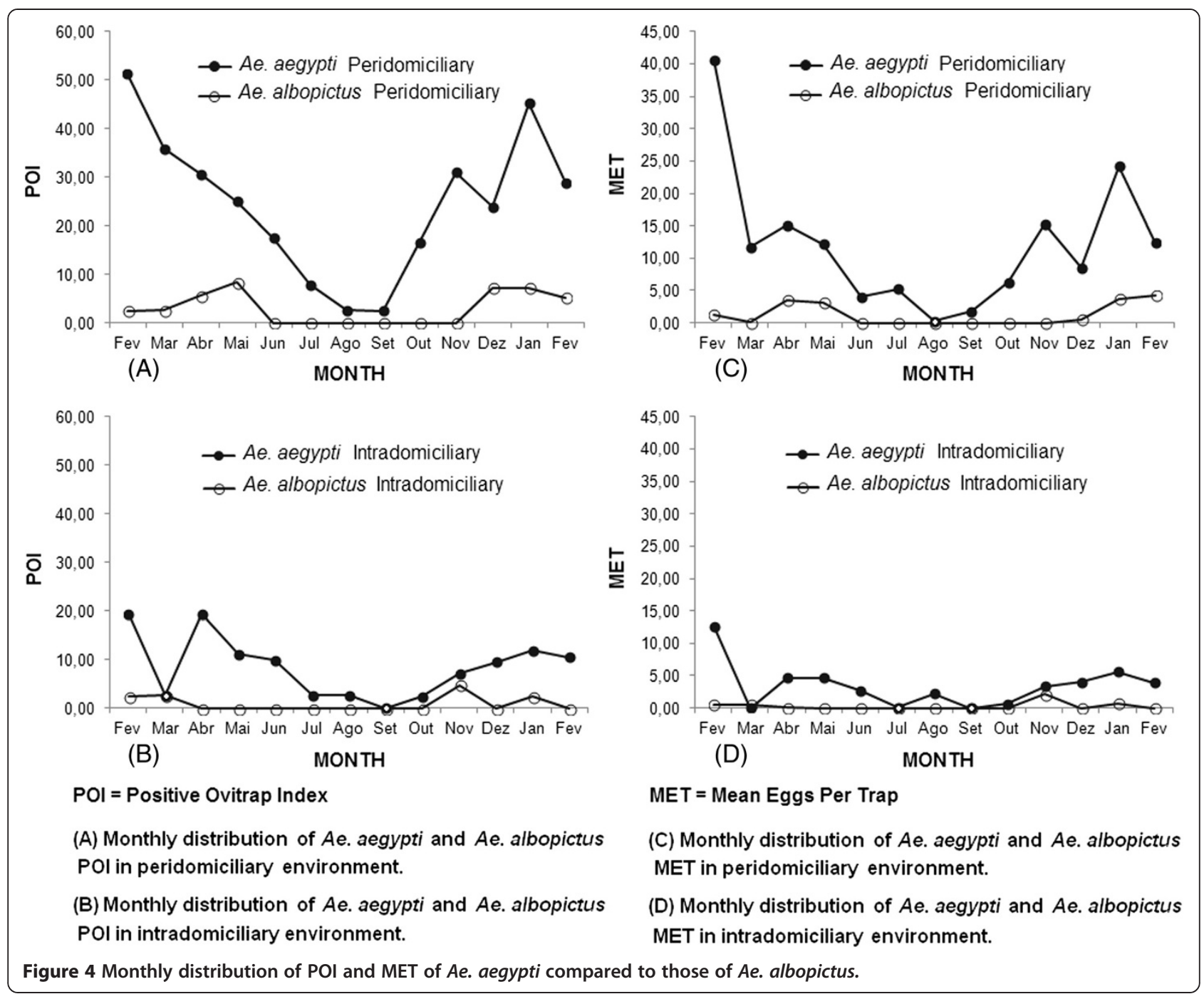

A, B. A constant and high positivity of Ae aegypti was noted in the peridomiciliary premises, compared with Ae. albopictus. A decreased positivity of Ae. aegypti was noted in months where Ae. albopictus was absent. The intradomiciliary environment had the lowest positivity for both species.

The MET monthly distribution of Ae. aegypti and Ae. albopictus recorded peaks in the same months as those showing trap positivity for both species (Figure 4, C and D).

Spearman's rank correlation and simple linear regression analyses between the temperature and the number of traps with eggs of both species per environment yielded significant values (Table 2). No statistically significant correlation was found between the rainfall accumulated during the least rainy months (February and May to October; $r=0.29 ; p=0.49$ ) and the rainiest months (March, April, and November to January; $r=0.60 ; p=0.28$ ) and the mean egg count of the respective periods.
Spearman's rank correlation was determined between the POI and MET of Ae. (Ste) spp. $(\mathrm{r}=0.94, \mathrm{p}=0.00)$.

\section{Discussion}

The research on Stegomyia eggs conducted in an urban, residential area of the municipality of São Sebastião from February 2011 to February 2012 revealed that $A e$. aegypti and Ae. albopictus are domesticated and able to lay eggs in peri- and intradomiciliary premises; however, Ae. aegypti was present in all 13 collections performed, whereas Ae. albopictus was present in a reduced number of collections.

The higher positivity of traps with Ae. aegypti showed this species' predominance over Ae. albopictus in peri- and intradomiciliary environments. Such results corroborate those recorded by Lim et al. [16] in two Malaysian fishing towns. Those authors reported that the sparse vegetation found in their study environment might have affected the data found. In the 
present study, this environment was considered the peridomiciliary setting.

The process of geographic expansion of these species from 1996 to 2000 in the study municipality exhibited a trend of prevalence of Ae. aegypti larvae over Ae. albopictus larvae. Such findings were recorded in artificial breeding grounds, which were deemed most likely responsible for the production and maintenance of Stegomyia populations at that time [22].

The MET of Ae. aegypti in this study was higher than the MET of Ae. albopictus in both domiciliary environments studied. This result was similar to the findings of other authors $[15,16,18]$. The superiority of Ae. aegypti in urban habitats in general is attributed to its high anthropophily and domesticity [4].

Comparisons of the POI of Ae. aegypti between periand intradomiciliary environments indicated the predominance of this species in the peridomicile. These results corroborate the findings of Dibo et al. [19] in their investigation of the best location to install $A e$. aegypti traps, which was conducted in a town in São Paulo State, Brazil.

The data reported herein characterized the peridomiciliary environment as primordial for gravid Ae. aegypti females in the selection of spaces for oviposition because the trap was placed both in peri- and intradomiciliary environments. Although females entered the homes to feed and rest, the gravid females found more suitable conditions for laying the eggs in the peridomiciliary environment. Chiaravalloti et al. [31] determined the relationship of this species with containers located in periand intradomiciliary premises, demonstrating that $A e$. aegypti is more associated with the vicinity of the house, whereas Ae. albopictus occupies natural and disposable breeding grounds in sites farther away from peridomiciliary premises.

The present study revealed similar distribution and abundance patterns for Ae. albopictus in both environments studied. This result coincides with the characteristics typical of this species, which preferentially occupies peridomiciliary premises, as reported by Foo et al. [32]. It is noteworthy that the trap sites in the peridomiciliary premises were generally closer to the residences. Dieng et al. [33] suggested that this finding demonstrates the adaptative behavior of Ae. albopictus to intradomiciliary premises, which may cause an increase in the vectorial capacity of the species. Such records have ecological implications of epidemiological impact because they express the proximity of this species to humans, given their proficiency in transmitting different types of viruses, because this species is present in urban, peri-urban, and wild environments [34,35].

Lim et al. [16] demonstrated a higher positivity of traps with Ae. albopictus in peridomiciles, and Norzahira et al.
[17] found a higher density and increased presence of $A e$. albopictus in that type of domiciliary environment.

The number of positive traps was three times higher (similar to the MET, which was four times higher) in the peridomiciliary environments than in the intradomiciliary environments; these values were always expressed in small numbers throughout the study, which might have affected the statistical analysis. The low POI and MET values of Ae. albopictus and its similar distribution between environments may result from larval competition with Ae. aegypti, which is an interaction supposedly occurring in local breeding grounds [36].

In contrast with São Sebastião, the dominance pattern of these species, as noted by Norzahira et al. [17] in Pahang, Malaysia, indicated that populations of Ae. albopictus were predominant over those of Ae. aegypti in both domiciliary environments. Those authors recorded a higher density of Ae. albopictus in peridomiciliary environments. Ae. aegypti presented a stable population in the study area of the above-mentioned investigation, although in a disadvantaged situation.

Rozilawati et al. [15] found a higher abundance of Ae. albopictus over Ae. aegypti when studying their seasonal abundance in exclusively peridomiciliary environments in Penang, Malaysia. The authors attributed the results to the installation of ovitraps only in peridomiciliary premises.

As suggested by various authors, the lower frequency of Ae. albopictus eggs in an urban space may result from the wild characteristics maintained by the species, which determine its superiority in areas of significant plant cover $[4,5,16]$. In São Sebastião, the urban characteristics apparently favor Ae. aegypti. The lack of statistically significant differences for the Ae. albopictus indicators does not mean that this species is less attracted to a given domiciliary environment because the number of specimens recorded in peridomiciliary premises was higher than that in intradomiciliary premises. Therefore, it is legitimate to ensure the existence of different patterns of habitat occupation exercised by Ae. aegypti and Ae. albopictus. Reiter [20] reported that the oviposition behavior in the field might vary significantly both between species and within a species, albeit in different regions. Such differences are apparently related to environmental heterogeneity and the impact that human activities have on these mosquitoes $[5,7,37,38]$.

Research studies conducted in Selangor, Malaysia, revealed no changes in the density of Ae. aegypti in domiciliary environments $[16,18]$. These similarities were interpreted as being caused by changes in the occupation pattern of Ae. aegypti in that region [16].

The present study demonstrated the effect of temperature on oviposition activities because a positive association was found between the temperature and the number of 
traps for both species and the number of Ae. aegypti specimens. The minimum, average, and maximum temperatures exhibited a positive association with the oviposition of Ae. aegypti in the peridomiciliary environment and with the average and maximum temperatures in the intradomiciliary environment. Within the residence, the minimum temperature may remain higher than in the peridomiciliary environment, consequently affecting the vector behavior, which requires additional studies. The association between the oviposition activity of Ae. aegypti and the temperature was clear, supported by the reductions in POI and MET that were recorded during the period from June to September, when the temperature decreased and the maximum temperature did not surpass $23.06^{\circ} \mathrm{C}$. The statistically significant association found between temperature and trap positivity and the mean egg count was reported by Dibo et al. [19].

Azil et al. [7] noted that the minimum and daily average temperatures were the most significant factors associated with short- and long-term vector abundance and suggested the prospective use of meteorological variables in predicting changes in the dengue-virus vector abundance.

The lack of association between the rainfall and the trap positivity and egg density for both species, as found in the present study, may be related to local climate characteristics, namely, a tropical rainy climate with frequent rainfall and no defined dry season. Notably, the trap is an attractive breeding ground during the period of exposure. Accordingly, the lack of correlation between the rainfall accumulated during the least rainy months and during the rainiest months and the egg count recorded during the respective periods has a timely explanation. Mogi et al. [39] and Miyasaki et al. [40] reported that rainfall is a key meteorological variable for regulating vector populations using breeding grounds located in peridomiciliary premises, especially in regions with a defined climate season, which does not occur in São Sebastião.

Gravid Ae. aegypti females presented a temporal pattern of permanent oviposition activity. Overall, the largest increases in trap positivity and egg density occurred during the months of higher temperatures, that is, from October (average temperature of $24.32^{\circ} \mathrm{C}$ ), stabilizing until February (minimum temperature of $20.14^{\circ} \mathrm{C}$ ). There was a decrease in oviposition activity after February, which continued until September, when the maximum temperature decreased to $21.48^{\circ} \mathrm{C}$. Such a seasonal profile of the Ae. aegypti population was previously found in the same study municipality using the house, container, and Breteau indices of infestation [22].

According to Vezzani et al. [41], the seasonal fluctuation in Ae. aegypti abundance enables the identification of the most appropriate moment for control intervention in the field. The highest values of the POI and MET of Ae. aegypti were recorded during the months with the highest temperatures, which was the most important environmental factor in vector biology at the local level.

The number of eggs collected using ovitraps from June to October, albeit small, suggests the existence of permanent breeding grounds in the area, which favors the maintenance of Ae. aegypti populations during the period that is least favorable to the vector, although at a low density. Souza et al. [42] reported that Ae. aegypti does not exclusively depend on the breeding grounds that emerge during the rainy period, thereby enabling this mosquito to maintain its life cycle during the dry period. For this purpose, permanent artificial breeding grounds are used, and although they are at a low density, they are sufficient to sustain transmission.

The presence of Ae. albopictus, in turn, was reduced, albeit with more expressive numbers, in the collections performed in May, December, and January. These last two months are among the months with highest infestation by this species, demonstrating a close relationship between its abundance and higher rainfall rates $[43,44]$. Different authors reported that seasonal changes in the oviposition of these species result from changes in climate conditions and the availability of oviposition sites $[1,44]$.

The strong correlation between the POI and MET of Ae. (Ste) spp. found in the present study may be considered an association predictive of abundance and frequency of these Stegomyia spp $[19,39]$. This result would imply waiving the egg count, indicating the moment for triggering the control measures. The use of this indicator may also contribute to reducing the Ae. aegypti numbers when the vector population increases. Such implications were indicated by Mogi et al. [45], Dibo et al. [19], and Regis et al. [46], corroborating the importance of using ovitraps.

Regarding Ae. aegypti, the peaks of POI and MET overlapped in both environments studied. Conversely, Ae. albopictus exhibited a similar behavior in the intradomiciliary premises, whereas the POI peaks in the peridomiciliary premises were accompanied by a reduction in MET, and the decrease in POI was accompanied by a trend toward an increased MET. The curve of Ae. albopictus might have resulted from the reduced number of mosquitoes existing in the area, thereby requiring a larger sample than that used in the present study.

The use of ovitraps exhibited the seasonal variation of the Ae. aegypti and Ae. albopictus species in an urban area of São Sebastião. However, the population dynamics of these mosquitoes also results from other bioecological determinants [47], which may represent a limitation of the present study.

In this investigation, using 1,028 ovitraps, 20,264 eggs were collected from urban residences, with a mean of 20 
eggs per trap. This result, combined with other control methods, may represent another strategy for reducing the population of Ae. aegypti through the large-scale removal of eggs, as suggested by Regis et al. [46].

The egg collection method was conclusively effective in assessing the distribution and abundance of $A e$. aegypti and Ae. Albopictus, based on ovitraps as an attractive solution and as a possible control tool for reducing the Ae. aegypti population.

\section{Conclusions}

The trap positivity and mean egg count of Ae. aegypti were clearly higher than those of Ae. albopictus. The peridomiciliary premise was the primary environment in which gravid Ae. aegypti females selected their oviposition site. The use of this method for vector surveillance and control activities is reiterated.

\section{Competing interests}

The authors declare they have no competing interests and the sponsors had no role in the study design, data collection and analysis, decision to publish, or preparation of the manuscript: Study of the distribution and abundance of the eggs of Aedes aegypti and Aedes albopictus according to the habitat and meteorological variables, municipality of São Sebastião, São Paulo, Brazil.

\begin{abstract}
Authors' contributions
LLNS: Conceived of the study, have made the conception and design acquisition of data, have been involved in drafting the manuscript and coordinated fieldwork. GRAMM: Guiding the study product thesis, has been involved in the realization revising it critically for important intellectual content participated in the preparation and writing of the manuscript. JCV: Has made substantial contributions to studies conducted analysis and interpretation of data. APL: Participated in the coordination of the work of data collection, carried out sample collection in the field and. carried out the larvae diagnostic work. MBA: Have been involved in the realization of the sample design, participated in the coordination of the work of data collection and helped to draft the manuscript. GLB: Helped to draft the manuscript and have been involved in the revised. VRB: Helped to draft the manuscript and have been involved in the revised. VLCL: Research project coordenator of which this study is a part of. Discussed data and made revising it critically for important intellectual content. All authors read and approved the final manuscript.
\end{abstract}

\section{Acknowledgements}

This study was supported by the Superintendência de Controle de Endemias (Suecen) under grant agreement no 000005/2011 and a Fundação de Amparo à Pesquisa do Estado de São Paulo (FAPESP) under grant agreement no 53123-7/2009. The authors thank the field team from the Sucen-SR3 (sector4) for operational support for the eggs sampling.

\section{Author details}

'Superintendência de Controle de Endemias, Praça Coronel Vitoriano, 23 Jardim Santa Clara, Centro, Taubaté, São Paulo CEP 12020-020, Brasil. ¿Universidade de Taubaté, Avenida Tiradentes, 500, Bom Conselho, Taubaté, São Paulo CEP 12030-180, Brasil. S Superintendência de Controle de Endemias, Rua Paula Souza, 166, Luz, São Paulo, São Paulo CEP 01027-000, Brasil. ${ }^{4}$ Superintendência de Controle de Endemias, Rua São Carlos, 546, Vila Industrial, Campinas, São Paulo CEP 13035-420, Brasil.

Received: 26 July 2013 Accepted: 10 October 2013

Published: 6 November 2013

\section{References}

1. Adeleke MA, Mafiana CF, Idowua AB, Sam-Woboa SO, Idowua AO: Population dynamics of indoor sampled mosquitoes and their implication in disease transmission in Abeokuta, south-western Nigeria. $J$ Vector Borne Dis 2010, 47:33-38.

2. Tauil PL: Controle de agravos á saúde: consistência entre objetivos e medidas preventivas. IESUS 1998, 7:55-58.

3. Tauil PL: Aspectos críticos do controle do dengue no Brasil. Cad Saude Publica 2002, 18:867-871.

4. Braks MAH, Honório NA, Lourenço-de-Oliveira R, Juliano SA, Lounibos PL: Convergent Habitat Segregation of Aedes aegypti and Aedes albopictus (Diptera: Culicidae) in Southeastern Brazil and Florida. J Med Entomol 2003, 40:785-794.

5. Honório NA, Castro MG, Barros FSM, Magalhães MAFM, Sabroza PC: The spatial distribution of Aedes aegypti and Aedes albopictus in a transition zone, Rio de Janeiro, Brazil. Cad Saude Publica 2009, 25:1203-1214.

6. Pessanha JEMP, Caiaffa WT, Almeida MCM, Brandão ST, Proietti FA: Diffusion Pattern and Hotspot Detection of Dengue in Belo Horizonte, Minas Gerais, Brazil. J Trop Med 2012, 44:103-105.

7. Azil AH, Long SA, Ritchie SA, Williams CR: The development of predictive tools for pre-emptive dengue vector control: a study of Aedes aegypti abundance and meteorological variables in North Queensland, Australia. Trop Med Int Health 2010, 15:1190-1197.

8. Focks DA, Haile DC, Daniels E, Mount GA: Dynamic life table model for Aedes aegypti: Simulations results. J Med Entomo 1993, 30:1019-1029.

9. Focks DA: A Review of Entomological Sampling Methods and Indicators for Dengue Vectors. Gainesville, Florida: World Health Organization; 2003:40.

10. Fay RW, Eliason DA: A preferred oviposition site as a surveillance method for Aedes aegypti. Mosq News 1966, 26:531-535.

11. Marques CC, Marques GR, Brito M, Santos Neto LG, Ishibashi VC, Gomes AC: Comparative study of larval and ovitrap efficacy for surveillance of dengue and yellow fever vectors. Rev Saude Publica 1993, 27:237-241.

12. Braga IA, Gomes AC, Nelson M, Mello RCG, Bergamaschi DP, Souza JMP: Comparação entre pesquisa larvária e armadilha de oviposição, para detecção de Aedes aegypti. Rev Soc Bras Med Trop 2000, 33:347-353.

13. Forattini OP, Kakitani I, Sallum MAM, Rezende L: Produtividade de criadouro de Aedes albopictus em ambiente urbano. Rev Saude Publica 1997, 31:545-555.

14. Donalisio MR, Glasser CM: Vigilância Entomológica e Controle de Vetores do Dengue. Rev Bras Epidemiol 2002, 5:259-272.

15. Rozilawati H, Zairi J, Adanan CR: Seasonal abundance of Aedes albopictus in selected urban and suburban areas in Penang, Malaysia. Trop Biomed 2007, 24:83-94.

16. Lim KW, Sit NW, Norzahira R, Sing KW, Wong HM, Chew HS, Firdaus R, Cheryl JA, Suria M, Mahathavan M, Nazni WA, Lee HL, McKemy A, Vasan SS: Dengue vector surveillance in insular settlements of Pulau Ketam, Selangor Malaysia. Trop Biomed 2010, 27:185-192.

17. Norzahira R, Hidayatulfathi O, Wong HM, Cheryl A, Firdaus R, Chew HS, Lim KW, Sing KW, Mahathavan M, Nazni WA, Lee HL, Vasan SS, McKemey A, Lacroix R: Ovitrap surveillance of the dengue vectors, Aedes (Stegomyia) aegypti (L.) and Aedes (Stegomyia) albopictus Skuse in selected areas in Bentong, Pahang, Malaysia. Trop Biomed 2011, 28:48-54.

18. Dhang CC, Benjamin S, Saranum MM, Fook CY, Lim LH, Ahmad NW, SofianAzirun M: Dengue vector surveillance in urban residential and settlement areas in Selangor, Malaysia. Trop Biomed 2005, 22:39-43.

19. Dibo MR, Chiaravalloti-Neto F, Battigaglia M, Mondini A, Favaro EA, Barbosa AAC, Glasser CM: Identification of the best ovitrap installation sites for gravid Aedes (Stegomyia) aegypti in residences in Mirassol, state of São Paulo, Brazil. Mem Inst Oswaldo Cruz 2005, 100:339-343.

20. Reiter P: Oviposition, Dispersal, and Survival in Aedes aegypti: Implications for the Efficacy of Control Strategies. Vector Borne Zoonotic Dis 2007, 7:261-273.

21. Minuzzi RB, Sediyama GC, Barbosa EM, Melo JCFJ: Climatologia do comportamento do período chuvoso da região sudeste do Brasil. Rev Bras Meteorol 2007, 22:338-344.

22. Passos RA, Marques GRAMM, Voltolini JC, Condino ML: Dominância de Aedes aegypti sobre Aedes albopictus no litoral sudeste do Brasil. Rev Saude Publica 2003, 37:729-734.

23. Ribeiro AF, Marques GRAM, Voltolini JC, Condino LMF: Associação entre incidência de dengue e variáveis climáticas. Rev Saude Publica 2006, 40:671-676

24. Setzer J: Atlas Climático e Ecológico do Estado de São Paulo. Ed. São Paulo: Comissão Interestadual da Bacia do Paraná-Uruguai em colaboração com as centrais elétricas de SP (CESP); 1966:35-39. 
25. Alves MCGP, Silva NN: Simplificação do método de estimação da densidade larvária de Aedes aegypti no Estado de São Paulo. Rev Saude Publica 2001, 35:467-473.

26. Chadee DD: Seasonal incidence and vertical distribution patterns of oviposition by Aedes aegypti in an urban environment in Trinidad, W.I. J Am Mosq Control Assoc 1991, 7:383-836.

27. Reiter P, Amador MA, Colon N: Enhancement of the CDC ovitrap with hay infusions for daily monitoring of Aedes aegypti populations. J Am Mosq Control Assoc 1991, 7:52-55.

28. Wong J, Astete H, Morrison AC, Scott TW: Sampling Considerations for Designing Aedes aegypti (Diptera:Culicidae) Oviposition Studies in Iquitos, Peru: Substrate Preference, Diurnal Periodicity, and Gonotrophic Cycle Length. J Med Entomol 2011, 48:45-52.

29. Consoli RAGB, Lourenço-de-Oliveira R: Principais mosquitos de importância sanitária no Brasil. Rio de Janeiro: Fiocruz; 1994

30. Zar JH: Biostatistical analysis. Canada: Prentice Hall; 2009.

31. Chiaravalloti FN, Dibo MR, Barbosa AAC, Battigaglia M: Aedes albopictus (S) na região de São José do Rio Preto, SP: estudo da sua infestação em área já ocupada pelo Aedes aegypti e discussão de seu papel como possível vetor de dengue e febre amarela. Rev Soc Bras Med Trop 2002, 35:351-357.

32. Foo LC, Lim TW, Lee HL, Fang R: Rainfall, abundance of Aedes aegypti and dengue infection in Selangor, Malaysia. Southeast Asian J Trop Med Public Health 1985, 16:560-568.

33. Dieng H, Saifur RGM, Hassan AA, Che Salmah MR, Boots M, Satho T, Jaal Z, AbuBakar S: Indoor-Breeding of Aedes albopictus in Northern Peninsular Malaysia and Its Potential Epidemiological Implications. PLOS ONE 2010, 7:e11790.

34. Marques GRAM, Forattini OP: Aedes albopictus em bromélias de solo em Ilhabela, litoral do Estado de São Paulo. Rev Saude Publica 2005, 39:548-552.

35. Paupy C, Ollomo B, Kamgang B, Moutailler S, Rousset D, Demanou M, Hervé $J$ P, Leroy E, Simard F: Role of Ae. albopictus versus Ae. aegypti in dengue and chikungunya emergences in Central Africa: laboratory and field evidence. Vector Borne Zoonotic Dis 2010, 10:259-266.

36. Serpa LLN, Kakitani I, Voltolini JC: Competição entre larvas de Aedes aegypti e Aedes albopictus em laboratório. Rev Soc Bras Med Trop 2008, 41:479-484.

37. Higa Y: Dengue Vectors and their Spatial Distribution. Trop Med Health 2011, 39:17-27.

38. Baruah S, Dutta P: Seasonal pattern of abundance of Aedes albopictus in urban and industrial areas of Dibrugarh District Assam. Asian J Exp Biol SCl 2012, 3:559-564.

39. Mogi M, Khamboonruang C, Choochote W: Ovitrap surveys of dengue vector mosquitoes in Chiang Mai, northern Thailand: seasonal shits in relative abundance of Aedes albopictus and Ae. aegypti. Med Vet Entomol 1988, 2:319-324.

40. Miyazaki RD, Ribeiro ALM, Pignatti MG, Campelo Júnior JH, Pignati M: Monitoramento do mosquito Aedes aegypti (Linnaeus, 1762) (Diptera: Culicidae), por meio de ovitrampas no Campus da Universidade Federal de Mato Grosso, Cuiabá, Estado de Mato Grosso. Rev Soc Bras Med Trop 2009, 42:392-397.

41. Vezzani D, Velázquez SM, Schweigmann N: Seasonal pattern of abundance of Aedes aegypti (Diptera: Culicidae) in Buenos Aires city, Argentina. Mem Inst Oswaldo Cruz 2004, 99:351-356.

42. Souza SS, Silva IG, Silva HHG: Associação entre incidência de dengue, pluviosidade e densidade larvária de Aedes aegypti, no Estado de Goiás. Rev Soc Bras Med Trop 2010, 43:152-155.

43. Marques GRAM, Gomes AC: Comportamento antropofílico de Aedes albopictus (Skuse) (Diptera: Culicidae) na região do Vale do Paraíba, Sudeste do Brasil. Rev Saude Publica 1997, 31:125-130.

44. Raharimalala FN, Ravaomanarivo LH, Ravelonandro P, Rafarasoa LS, Zouache K, Tran-Van V, Mousson L, Failloux AB, Hellard E, Moro CV, Ralisoa BO, Mavingui P: Biogeography of the two major arbovirus mosquito vectors, Aedes aegypti and Aedes albopictus (Diptera, Culicidae), in Madagascar. ParasitVectors 2012, 5:56.

45. Mogi M, Choochote W, Khamboonruang C, Swanpanit P: Applicability of presence-absence sampling for ovitrap surveillance of Aedes (Diptera: Culicidae) in Chiang Mai, Northern Thailand. J Med Entomol 1990, 27:509-514

46. Regis L, Monteiro AM, Melo-Santos MAV, Silveira JC Jr, Furtado AF, Acioli RV, Santos GM, Nakazawa M, Carvalho MS, Ribeiro PJJ, Souza WV: Developing new approaches for detecting and preventing Aedes aegypti population outbreaks: basis for surveillance, alert and control system. Mem Inst Oswaldo Cruz 2008, 103:50-59.

47. Lucio OS, Degallier N, Servain J, Hannart A, Durand B, de Souza RN, Ribeiro ZM: A case study of the influence of local weather on Aedes aegypti (L.) aging and mortality. J Vector Ecol 2013, 38:20-37.

doi:10.1186/1756-3305-6-321

Cite this article as: Serpa et al:: Study of the distribution and abundance of the eggs of Aedes aegypti and Aedes albopictus according to the habitat and meteorological variables, municipality of São Sebastião, São Paulo State, Brazil. Parasites \& Vectors 2013 6:321.

\section{Submit your next manuscript to BioMed Central and take full advantage of:}

- Convenient online submission

- Thorough peer review

- No space constraints or color figure charges

- Immediate publication on acceptance

- Inclusion in PubMed, CAS, Scopus and Google Scholar

- Research which is freely available for redistribution

Submit your manuscript at www.biomedcentral.com/submit
C Biomed Central 